\title{
Corrosive Poisoning- a Case report with Literature of Review
}

\author{
Rawal $\mathbf{G}^{1}$, Garg $\mathbf{N}^{2}$, Wani UR ${ }^{3}$, Yadav $\mathbf{S}^{4}$ \\ ${ }^{1}$ Dr Gautam Rawal, Attending Consultant, ${ }^{2}$ Dr Nitin Garg, Senior consultant and Head, ${ }^{3}$ Dr Umar Rasool Wani, Senior \\ Resident. All are affiliated to Critical Care Department, Rockland Hospital, Qutab Institutional Area, New Delhi, India, ${ }^{4}$ Dr \\ Sankalp Yadav, General Duty Medical Officer-II, Chest Clinic Moti Nagar, New Delhi, India
}

Address for Corresponding: Dr Gautam Rawal, Attending Consultant-Critical Care, Rockland Hospital, Qutab Institutional Area, New Delhi, India, Email: drgautamrawal@hotmail.com

\begin{abstract}
Corrosive gastrointestinal tract injuries are a source of considerable mortality and morbidity all over the world. Despite this, the actual data on the epidemiology of the poisoning/ingestion are scarce due to lack of well established reporting system for poisoning in most countries. The burden of this poisoning is naturally more in developing countries like India, where the condition is common because of poorly regulated sale of corrosive substances. The authors here present you a case of a young male who had accidental acid ingestion and complications and was managed under them, with review of the management of corrosive ingestion.
\end{abstract}

Key words: Corrosive poisoning, Acid ingestion, Acid Injuries, pyloric stenosis, Corrosive poisoning

\section{Introduction}

The Modern technology has come with its own dreaded consequences of synthesizing chemical substances with strong corrosive nature that are often used in everyday life [1]. Corrosive gastritis results primarily from ingestion, either accidentally or with suicidal intent, of commercially available mineral acids such as hydrochloric, sulfuric, nitric and carbolic acids or corrosive alkalis. In majority of the presenting cases, the mode of entry of corrosive in human body is oral (ingestion) with only rare cases of inhalational injury (corrosive vapors). Corrosive injuries are an important cause of morbidity and mortality all over the world, with major burden being present in the developing countries, including India.

Both acid and alkalis produce considerable and progressive injuries to the upper gastrointestinal tract. Corrosive agents are available easily as household items and do not come under any strict regulatory control of an authority to check their sale.

The case presented here was admitted under the authors care as a result of accidental ingestion of acid (toilet cleaner). The patient developed complications of

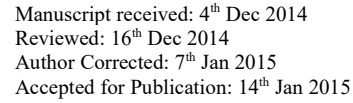

International Journal of Medical Research and Review corrosive ingestion: oesophageal stricture, gastric outlet obstruction due to pyloric stenosis and underwent sideto-side gastroduodenojejunostomy. He is now doing well, accepting oral food and being followed up as an outpatient.

\section{Case Report}

A young male, 24 years old, was brought to Rockland Qutab emergency department, with history of accidental ingestion of about $10-15 \mathrm{ml}$ of acid (toilet cleaner) followed by severe burning sensation in throat, retrosternum and epigastrium. This was followed by multiple episodes of vomiting, few episodes of haematemesis and severe retching. He was admitted in intensive care unit (ICU), given intravenous fluids, proton pump inhibitors (PPI), anti-emetics, analgesia with intravenous fentanyl and empirical antibiotic. On examination his blood pressure was $120 / 70 \mathrm{mmHg}$, heart rate $95 /$ minute, respiratory rate 20 /minute with an oxygen saturation of $98 \%$ on room air, normal systemic examination except for epigastric tenderness. There was no sign of respiratory distress or perforation of viscera. Gastroenterolgy team planned for an upper gastrointestinal (UGI) endoscopy within 24 hours of ingestion which revealed grade $2 \mathrm{a}$ injury to the gastric mucosa [4]. A diagnosis of corrosive gastritis was made. 
His vitals and blood haemoglobin remained stable with no further haematemesis and he discharged after 4 days, on oral liquid diet with advice for a regular follow-up. He had dysphagia to solid and semi-solid food even after more than a month of ingestion. He was managed as a day-care patient with anti emetics and intravenous fluids and nutrition. He was admitted again for UGI endoscopy which showed stricture of esophagus [Image:1], pylorus up to duodenum which was also confirmed on computed tomogram (CT) scan of abdomen. His feeding jejunostomy was done. Later sequential dilatations of esophagus were performed endoscopically with success but still he could not tolerate oral feeds and had features of gastric outlet obstruction. After about 6 months of ingestion, he underwent side to side gastroduodenostomy with closure of feeding jejunostomy and discharged on oral feeds. He is doing well with adequate oral intake and is being regularly followed-up.

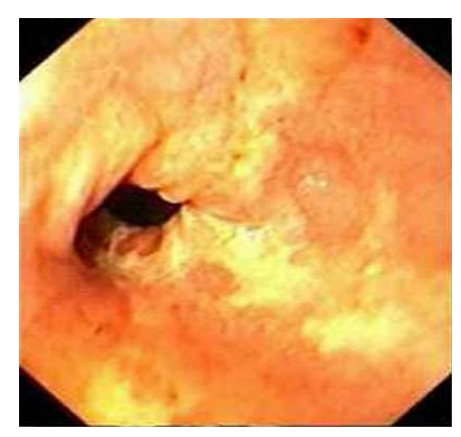

Image 1: Endoscopic view of oesophageal stricture

\section{Discussion}

Corrosive ingestion, most commonly acid, is a common form of poisoning in India as it's cheap and easily available as toilet cleaner (sulphuric acid/ hydrochloric acid). The most common reason for ingestion is suicidal with cases of accidental ingestion arecalso reported (more in children or person with mental disorder) [1]. The most serious and extensive injury occurs in the oesophagus and stomach as they are in contact with the corrosive agent for the longer period.

The severity and the relative extent of the chemical injury/burns from corrosive ingestion depend on the quantity, concentration and physical form (solid/liquid) of the agent and also duration of contact with the mucosa and $\mathrm{pH}$ of agent and the titratable acid or alkaline reserve (the amount of acid or base required to neutralize the agent).

Acids and alkalis both cause fibrosis and stricture formation. Alkalis cause liquefaction necrosis, resulting in penetrating injury to the oesophageal mucosa till it gets buffered by the tissue fluids. Injury to the stomach mucosa is limited due to neutralization by the acid in stomach. Acids cause coagulation necrosis, leading to cell death and eschar formation. This process limits the penetration and protects against deeper injury.

Clinical presentation of corrosive injuries often may not correlate with the severity and extent of tissue injury [1].
Patient complains of oropharyngeal, epigastric, or retrosternal pain associated with dysphagia or odynophagia, and / or hypersalivation. Injury to oropharynx causes severe pain with inability to clear pharyngeal secretions resulting in drooling.

Severe persistent retrosternal or back pain indicates esophageal perforation with mediastinitis. Persistent and recurrent vomiting (many times associated with hematemesis), localized abdominal pain with rebound tenderness and rigidity indicates visceral (esophageal or gastric) perforation with peritonitis.

Endoscopy: Upper gastrointestinal (UGI) endoscopy should be performed during the first 24 hours after ingestion in order to evaluate the extent of esophageal and gastric damage, establish prognosis, and guide therapy $[2,3]$.

Endoscopy if done very early ( $<6$ hours) may not reveal the full extent of injury due to the mucosal erythema. The commonest practice is to perform endoscopy on Day 1-2. UGI endoscopy is not recommended between 5 and 15 days after the ingestion due to high risk of perforation.

Esophageal injury/burns, secondary to acid ingestion, are classified based on endoscopic visualization based on a grading system similar to that used with burns of the skin [4] : 


\section{Grade Description}

0 Normal mucosa

1 Erythema/Hyperemia

2a Superficial ulcer/erosion/friability/ haemorrhage/ exudates

2b Findings in $2 \mathbf{a}+$ deep discrete/circumferential ulcers 3a Scattered/Focal necrosis (black/grey discoloration)

3b Extensive/circumferential necrosis of mucosa

Neutralization of corrosives is contraindicated as it generates heat and increases the risk of aspiration. Antibiotics are recommended in grade 3 injury and suspected gastrointestinal perforation but there is no role of prophylactic antibiotics, as tissue destruction by caustic injury increases the risk of infection by enteric organisms. Proton pump inhibitors and $\mathrm{H} 2$ blockers are routinely recommended. Nutrition is planned according to the endoscopic grade of the lesions. Patients with grade $1 / 2 \mathrm{a}$ can tolerate oral feeds and those with grade $2 b / 3 a$ will require naso-enteral feeding. Patients with grade $3 b$ lesions require gastrostomy for enteral feeding and may even require total parenteral nutrition $[5,6]$.

\section{Complications}

Acute: Airway compromise: In the presence of respiratory distress and airway edema, urgent endotracheal intubation is indicated, as airway edema develops rapidly, leading to upper-airway obstruction. If the epiglottis or the larynx is edematous on direct layrngoscopy, endotracheal intubation is contraindicated and a tracheostomy or cricothyrotomy should be performed for airway control. There is no clear role for systemic steroids/adrenaline (intravenous or nebulised) in decreasing airway edema.

Shock: Usually occurs due to hypovolemiahaemorrhage, vomiting and third-space sequestration and stability can be achieved with intravenous fluids (crystalloid) and blood products if required.

GI perforation: It can cause esophageal leak/rupture and mediastinitis or gastric leak/bleed leading to peritonitis[7].

Aspiration pneumonia, respiratory distress (including ARDS)

- Late: Stricture/obstruction

- Remote: Carcinoma esophagus. Patients who develop esophageal strictures after caustic (especially alkali) ingestion have high risk (1,000 time higher risk than general population) for developing sqamous cell carcinoma of oesophagus, the mean latency period being about 41 years after ingestion. [3,8]

\section{Stricture management}

About one-third of patients with corrosive esophageal injury develop esophageal strictures, mainly in those with grade $2 \mathrm{~B}$ or 3 injuries. The peak incidence of dysphagia post corrosive ingestion (due to esophageal stricture) is observed at two months, though it may occur as early as two weeks to as late as years after ingestion $[7,8]$.

Dilatation therapy: Endoscopic dilatation of the esophageal stricture is done usually 3-6 weeks after the corrosive ingestion due to high risk of perforation, if done early. The desired goal is to dilate the esophageal lumen to about $15 \mathrm{~mm}$ and to relieve dysphagia for symptomatic comfort to the patient [8]. The risk of aspiration, perforation, and dysphagia still remains high.

Surgery: Indicated in the patients with strictures resistant to dilatation therapy. It includes resection of the esophageal segment (esophagectomy) or esophageal bypass [7,9]. Need to perform surgery for caustic injuries has been seen to have a persistent long-term negative impact on survival and functional outcome of the patients.

\section{Conclusion}

Corrosive ingestion produces severe injury to the gastrointestinal tract. It is one of the important causes of morbidity and mortality in developing countries, where the majority of the cases are suicidal. Acid ingestion is more common than alkali ingestion. Stringent legislative laws are necessary in these countries to curtail unrestricted access to corrosive substances.

Early upper GI endoscopy is now regarded to have a very crucial role in both diagnosis and management of the patients with corrosive ingestion. Patients with grade 0 and 1 injuries require only observation and can be managed as out-patients, while patients with grade 2 and 3 injury will require hospital admission and are at risk to develop complications.

\section{References}

1. Chand-Meena M, Rahul B, Mittal S. Accidental Corrosive Acid Intoxication- a Case Report. International Journal of Medical Toxicology and Forensic Medicine.2014; 4(3): 108-112 
2. Sugawa C, Mullins RJ, Lucas CE, Leibold WC. The value of early endoscopy following caustic ingestion. Surg Gynecol Obstet. 1981 Oct;153(4):553-6.

3. Cheng H-T, Cheng C-L, Lin C-H, et al. Caustic ingestion in adults: The role of endoscopic classification in predicting outcome. BMC Gastroenterology 2008;8:31. doi:10.1186/1471-230X-8-31

4. Zargar SA, Kuchhar R, Mehta S. The role of fibroptic endoscopy in the management of corrosive ingestion and modified endoscopic classification of burns. Gastrointest Endosc. 1991;37:165-9

5. Lu, Lung-Sheng et al. "Predicting the Progress of Caustic Injury to Complicated Gastric Outlet Obstruction and Esophageal Stricture, Using Modified Endoscopic Mucosal Injury Grading Scale.” BioMed Research International 2014 (2014): 919870. PMC. Web. 22 Jan. 2015 .

6. Nunez O., Gonzales-Asanza C. Study of predictive factors of severe digestive lesions due to caustics ingestion, Med Clin (Barc).2004 Nov; 123(16): 611-4.
7 Cattan P, Munoz-Bongrand N, Berney T, Halimi B, Sarfati E, Celerier M. Extensive Abdominal Surgery After Caustic Ingestion. Annals of Surgery 2000;231(4):519-523.

8. MAMEDE, Rui Celso Martins and MELLO FILHO, Francisco Veríssimo de. Ingestion of caustic substances and its complications. Sao Paulo Med. J. [online]. 2001, vol.119, n.1 [cited 2015-01-22], pp. 10-15 . Available from:

$<\mathrm{http}$ ://www.scielo.br/scielo.php?script=sci_arttext\&pid $=\mathrm{S} 1516-31802001000100004 \& \operatorname{lng}=\mathrm{en} \& \mathrm{nrm}=\mathrm{iso}>$. ISSN 1516-3180. http://dx.doi.org/10.1590/S151631802001000100004 .

9. Okonta KE, Tettey M, Abubakar U. In patients with corrosive oesophageal stricture for surgery, is oesophagectomy rather than bypass necessary to reduce the risk of oesophageal malignancy? Interactive Cardiovascular and Thoracic Surgery 2012;15(4):713715. doi:10.1093/icvts/ivs320.

\section{How to cite this article?}

Rawal G, Garg N, Wani UR, Yadav S. Corrosive Poisoning- A Case report with Literature of Review. Int J Med Res Rev 2015;3(1):132-135. doi: 10.17511/ijmrr.2015.i1.23 